- Effective cleaning is an essential pre-requisite for reliable sterilisation of dental instruments.

- This study reports on the observation of techniques used for cleaning instruments prior to sterilisation in dental practice.

- Direct observation of the cleaning processes provides reliable information on how this is undertaken in general dental practice.

- There are a number of working practices that can improve the cleaning of dental instruments and reduce the risks of cross-infection.

\title{
Pre-sterilisation cleaning of re-usable instruments in general dental practice
}

\author{
J. Bagg, ${ }^{1}$ A. J. Smith, ${ }^{2}$ D. Hurrell, ${ }^{3}$ S. McHugh ${ }^{4}$ and G. Irvine ${ }^{5}$
}

Objective This study examined the policies, procedures, environment and equipment used for the cleaning of dental instruments in general dental practice.

Materials and methods A total of 179 surgeries were surveyed. This was an observational based study in which the cleaning processes were viewed directly by a trained surveyor. Information relating to surgery policies and equipment was also collected by interview and viewing of records. Data were recorded onto a standardised data collection form prepared for automated reading.

Results The BDA advice sheet A12 was available in 79\% of surgeries visited. The most common method for cleaning dental instruments was manual washing, with or without the use of an ultrasonic bath. Automated washer disinfectors were not used by any surgery visited. The manual wash process was poorly controlled, with $41 \%$ of practices using no cleaning agent other than water. Only $2 \%$ of surgeries used a detergent formulated for manual washing of instruments. When using ultrasonic baths, the interval that elapsed between changes of the ultrasonic bath cleaning solution ranged from two to 504 hours (median nine hours). Fifty-eight percent of surgeries claimed to have a dedicated area for instrument cleaning, of which $80 \%$ were within the patient treatment area. However, in $69 \%$ of surgeries the clean and dirty areas were not clearly defined. Virtually all cleaning of dental instruments was undertaken by dental nurses. Training for this was provided mainly by demonstration and observed practice of a colleague. There was little documentation associated with training. Whilst

${ }_{1}$ Professor of Clinical Microbiology, ${ }^{2 *}$ Senior Lecturer in Microbiology, Infection Research Group, Glasgow Dental Hospital and School, 378 Sauchiehall Street, Glasgow, G2 3JZ; ${ }^{3}$ Decontamination Consultant, HealthCare Science Ltd, Unit 4, Northend Industrial Estate, Burymead Road, Hitchin, SE5 1RT; ${ }^{4}$ Statistician, ${ }^{5}$ Infection Control Nurse, Infection Research Group, University of Glasgow Dental School, 378 Sauchiehall Street, Glasgow, G2 3JZ

${ }^{*}$ Correspondence to: Dr Andrew J. Smith

Email:a.smith@dental.gla.ac.uk

\section{Online article number E22}

Refereed Paper - accepted 18 April 2006

DOI: $10.1038 /$ bdj.2007.124

${ }^{\circledR}$ British Dental Journal 2007; 202: E22 most staff wore gloves when undertaking manual cleaning, 51\% of staff did not use eye protection, 57\% did not use a mask and 7\% used waterproof overalls.

Conclusions In many dental practices, the cleaning of re-usable dental instruments is undertaken using poorly controlled processes and procedures, which increase the risk of cross infection. Clear and unambiguous advice must be provided to the dental team, especially dental nurses, on appropriate equipment, chemicals and environment for cleaning dental instruments. This should be facilitated by appropriate training programmes and the implementation of quality assurance procedures at each stage of the cleaning process.

\section{INTRODUCTION}

The decontamination of re-usable medical devices is a key element of infection control in clinical settings. The importance of cleaning such devices as a means of preventing cross infection has been reported in relation to diverse items of equipment in many areas of clinical practice. These have included ophthalmology, ${ }^{1}$ gastroenterology, ${ }^{2}$ vascular surgery, ${ }^{3}$ tourniquets $^{4}$ and dental surgery. ${ }^{5-9}$

More recently, the emergence of transmissible spongiform encephalopathies (TSEs), such as variant Creutzfeldt-Jakob disease (vCJD), has re-emphasised the importance of thorough cleaning of used devices prior to steam sterilisation ${ }^{10,11}$ since the abnormal form of prion protein, which is responsible for these diseases, is less susceptible to denaturation by heat. Thus, efficient cleaning of instruments is believed to be a key procedure for reducing the potential risks of onward transmission of vCJD. ${ }^{10-12}$ Effective cleaning is also vital to ensure microbial inactivation since retention of organic or inorganic debris may compromise subsequent disinfection or sterilization processes..$^{13-16}$ The cleaning of re-usable dental instruments is also important to ensure device longevity and functionality, removal of chemical residues and compliance with medicolegal directives. ${ }^{17-19}$

One mechanism for improving the quality of instrument decontamination is to centralise re-processing in 
well-equipped sterile services departments, which are operated by highly trained staff, using validated equipment, in an accredited quality management system. In the UK, this approach has been applied in the acute hospital sector. The problem with this centralised model in dentistry is that the high volume of instruments used by dental surgeons provides a significant logistical challenge. It is therefore likely that instrument decontamination in general dental practice will continue to be undertaken at a local level. It is important that all processes involved in decontamination are undertaken to a high standard, but unfortunately there has been little evidence to indicate the robustness of these procedures in dental practice, as highlighted in a systematic review. ${ }^{20}$ In order to address this problem, a large observational study of decontamination procedures in general dentistry in Scotland was devised and has recently been completed. This paper reports the data generated by the study in relation to procedures used by dentists for pre-cleaning of instruments prior to the sterilisation phase.

\section{MATERIALS AND METHODS}

\section{Survey methodology}

This has previously been reported in detail. ${ }^{21}$ In brief, the study population comprised all general dental practitioners in Scotland with a National Health Service (NHS) list number ( $\mathrm{n}=$ 837). This list was the basis for randomly selecting practitioners to survey. A total of 184 surgeries were surveyed, with usable data obtained from 179 surgeries.

\section{Data collection}

Each surgery was surveyed by a team of two, an infection control/decontamination expert and an experienced dental practitioner. The survey team interviewed the dental practitioner and dental nurse, reviewed documentation relevant to the survey and recorded the physical layout of the premises. The decontamination processes, including instrument cleaning procedures, undertaken by the surgery nurse were viewed directly by a member of the survey team. All relevant data were recorded onto data collection forms prepared for automated reading. ${ }^{21}$ The survey visits ran from January 2003 until the end of March 2004.

\section{Technical requirements and guidance}

The data collection forms of the survey were based on a number of technical requirements and guidelines, such as SHTM $2030^{22} /{\mathrm{HTM} 2030,{ }^{23} \text { BDA A12 }}^{24}$ and the Glennie Framework, ${ }^{25}$ with those elements relevant to the cleaning processes briefly summarised in Tables 1-4. In addition, data were collected to examine compliance with a number of legal requirements to ensure appropriate facilities and management processes were in place in surgeries. These include the Consumer Protection Act, ${ }^{18}$ the Medical Devices Regulations 2002, ${ }^{19}$ the Health and Safety at Work etc Act $1974^{17}$ and Management of Health and Safety at Work Regulations $1992 .{ }^{26}$

\section{RESULTS}

Personnel involved in instrument cleaning

Virtually all cleaning of re-usable instruments was undertaken by dental nurses. In addition, on occasions instrument reprocessing was undertaken by dentists (42\%), dental hygienists (37\%), ancillary staff (2\%) and receptionists (1\%). Only in a minority of surgeries (7\%) was there one or more members of staff whose sole or principal duties were concerned with the reprocessing of re-usable instruments and in this small number of surgeries these staff were generally dental nurses.

\section{Staff health and safety}

In relation to staff safety, the majority of those undertaking the manual washing wore gloves (99\%). However, 51\% of staff did not use eye protection, 57\% did not use a protective face mask and 93\% did not use waterproof overalls.

\section{Staff training}

Staff training for instrument cleaning was provided mainly by demonstration and observed practice of a working colleague. Only 10\% of surgeries had documented evidence of staff training.

\section{Location used for undertaking cleaning}

In 38\% of surgeries, the area for decontamination was physically separated from other work areas. Fifty-eight percent of surgeries had an associated dedicated area for the cleaning of used dental instruments and, of these, 80\% were within the surgery itself ie in the treatment area. However, in 69\% of surgeries the clean and dirty areas were not clearly defined. For the $42 \%$ of surgeries that did not have a dedicated area for cleaning dental instruments, a wide variety of activities were undertaken in the same area as cleaning, for example food and beverage preparation, general work surface, preparation of restorative materials and mixing of impression material.

In the areas where cleaning was undertaken, the majority (85\%) were essentially easy to clean and had smooth, washable non-slip floors, although most surgeries (76\%) did not have coved junctions between the walls and floors to facilitate cleaning of the floors.

For ventilation of the area in which cleaning was carried out, $20 \%$ of the areas were mechanically ventilated, with only $4 \%$ providing extract ventilation over the manual wash sink to minimise aerosol dispersion.

The majority of dirty instruments were passed by hand on a tray to the area for cleaning. In 57\% of cleaning locations there was an obvious flow of work from clean to dirty to sterile without cross-over and in 59\% the flow of work minimised the risk of re-contamination between clean and dirty instruments.

The majority of surgeries (70\%) did not reprocess instruments as individual sets and 78\% did not use the same instrument tray with the same set of instruments. Instrument trays were cleaned on all occasions by $68 \%$ of surgeries, only when visibly soiled by $23 \%$ and never cleaned by $3 \%$.

\section{Methods of instrument cleaning}

Table 5 summarises the methods used by the surgeries to clean their re-usable instruments. Most surgeries used a combination of manual washing and ultrasonic cleaning, although not all instruments within a surgery were re-processed this way. For example, some devices, such as handpieces, are not recommended by the manufacturer to be cleaned in an ultrasonic bath. 
Table 1 Management of infection control in relation to cleaning of instruments

\begin{tabular}{|c|c|c|}
\hline Topic & Parameter(s) & Key indicators of good practice \\
\hline $\begin{array}{l}\text { Management of } \\
\text { infection } \\
\text { control }\end{array}$ & $\begin{array}{l}\text { Provide details of } \\
\text { infection control policies, } \\
\text { staff communication and } \\
\text { staff training in cleaning } \\
\text { of instruments prior to } \\
\text { sterilisation }\end{array}$ & $\begin{array}{l}\text { *All members of the dental team must know who is responsible for ensuring certain activities are carried out } \\
\text { and to whom to report any accidents or incidents. The individual practitioner must ensure that all members } \\
\text { of the dental team understand and practice these procedures routinely. } \\
\text { **Senior member of staff with responsibility for decontamination processes and capable of assessing and } \\
\text { treating risks associated with ineffective decontamination processes. } \\
{ }^{*} \text { Each practice must have a written infection control policy. }\end{array}$ \\
\hline $\begin{array}{l}\text { Staff and health } \\
\text { \& safety }\end{array}$ & $\begin{array}{l}\text { Collect data relating to the } \\
\text { measures taken to protect } \\
\text { the health and safety of } \\
\text { staff undertaking } \\
\text { decontamination and the } \\
\text { training received by staff in } \\
\text { respect of cleaning } \\
\text { instruments }\end{array}$ & $\begin{array}{l}{ }^{*} \text { All new staff must be appropriately trained in infection control procedures. Training should equip staff to } \\
\text { understand how infections are transmitted, the practice policy on decontamination and infection control, } \\
\text { what personal protection is required and when to use it, what to do in the event of accidents or } \\
\text { personal injury. } \\
{ }^{*} \text { It is useful for each member of staff to receive a copy of the infection control policy and to sign a } \\
\text { declaration that the policy has been received and the training provided. } \\
{ }^{* *} \text { All personnel carrying out decontamination processes have documented training needs assessment and } \\
\text { record of training received. }\end{array}$ \\
\hline
\end{tabular}

*Taken from BDA Advice Sheet $\mathrm{A} 12^{24} \quad{ }^{* *}$ Taken from the Glennie Framework ${ }^{25}$

Table 2 Assessment of the environment and work flow for cleaning dental instruments

\begin{tabular}{|c|c|c|}
\hline Topic & Parameter(s) & Key indicators of good practice \\
\hline $\begin{array}{l}\text { Environment } \\
\text { and workflow }\end{array}$ & $\begin{array}{l}\text { Gathers information which } \\
\text { describes the facilities } \\
\text { available for the cleaning of } \\
\text { instruments and examines } \\
\text { the movement of clean and } \\
\text { dirty instruments within } \\
\text { the surgery and practice }\end{array}$ & $\begin{array}{l}\text { *Where possible, instruments should be decontaminated away from the surgery in a room } \\
\text { containing the autoclave(s), ultrasonic bath(s), instrument washer(s) and sinks and a separate hand } \\
\text { wash basin. } \\
{ }^{*} \text { Clean and dirty areas within the surgery should be clearly defined. } \\
{ }^{*} \text { The area to be used for manual cleaning should be dedicated for the purpose and not shared with other } \\
\text { activities. This may be achieved by dedicating a zone to the cleaning process and segregating dirty from } \\
\text { clean by appropriate workflow patterns and practices. } \\
{ }^{* * A} \text { dedicated sink (not hand wash basin), to contain water/detergent mixture for cleaning instruments, } \\
\text { should be provided. }\end{array}$ \\
\hline
\end{tabular}

*Taken from BDA Advice Sheet A1224 ${ }^{* *}$ Taken from the Glennie Framework ${ }^{25}$

Table 3 Equipment used for cleaning

\begin{tabular}{l|l|l}
\hline Topic & Parameter(s) & Key indicators of good practice \\
\hline $\begin{array}{l}\text { Manual } \\
\text { cleaning }\end{array}$ & $\begin{array}{l}\text { Gathers information on the } \\
\text { extent to which manual } \\
\text { cleaning is employed and } \\
\text { how manual cleaning is } \\
\text { carried out }\end{array}$ & $\begin{array}{l}{ }^{*} \text { Instruments should be fully immersed in a sink pre-filled with warm water and detergent. } \\
{ }^{* *} \text { Manual cleaning would normally be undertaken either by employing immersion or non-immersion } \\
\text { techniques depending on the construction of the device. }\end{array}$ \\
\hline $\begin{array}{l}\text { Ultrasonic } \\
\text { cleaner }\end{array}$ & $\begin{array}{l}\text { Gathers information } \\
\text { concerning ultrasonic } \\
\text { cleaners }\end{array}$ & $\begin{array}{l}\text { *Ultrasonic cleaners should contain a detergent not a disinfectant. } \\
\text { *The liquid in the ultrasonic cleaner should be disposed of at the end of each clinical session and more } \\
\text { often if it appears heavily contaminated. } \\
{ }^{*} \text { At the end of each day, the ultrasonic cleaner must be emptied. } \\
{ }^{* *} \text { There must be a procedure to ensure change of water at not more than four-hourly intervals. } \\
\text { e*Ultrasonic cleaners must be tested on installation, and weekly, using the aluminium foil erosion test to }\end{array}$ \\
\hline ensure continued ultrasonic activity.
\end{tabular}

Table 4 Instrument inspection post-cleaning

\begin{tabular}{l|l|l}
\hline Topic & Parameter(s) & Key indicators of good practice \\
\hline $\begin{array}{l}\text { Post-cleaning } \\
\text { inspection }\end{array}$ & $\begin{array}{l}\text { Collects data about the } \\
\text { procedures used for } \\
\text { inspecting cleaned instru- } \\
\text { ments prior to their being } \\
\text { sterilised }\end{array}$ & $\begin{array}{l}{ }^{*} \text { After cleaning, all instruments must be examined thoroughly and, if there is residual debris, re-cleaned. } \\
{ }^{*} \text { Following cleaning, all instruments should be carefully examined for organic material and/or damage } \\
\text { (under magnification where appropriate). Where practicable the inspection and functional testing of } \\
\text { surgical instruments should be carried out by a person not responsible for cleaning the item. Those persons } \\
\text { carrying out these tasks have a responsibility for ensuring that the items are fit for re-use. Records of all } \\
\text { work performed, including functional testing, should be maintained. }\end{array}$ \\
\hline \multirow{2}{*}{ *Taken from BDA Advice Sheet A1224 ${ }^{* *}$ Taken from the Glennie Framework ${ }^{25}$}
\end{tabular}




\begin{tabular}{|c|c|}
\hline Method & Number \\
\hline Manual washing only & 10 \\
\hline Ultrasonic cleaning only & 5 \\
\hline Manual washing $(+\mid-$ ultrasonic cleaning $)$ & $164^{*}$ \\
\hline Washer/disinfector & 0 \\
\hline
\end{tabular}



Fig. 1 Agents used to manually clean instruments

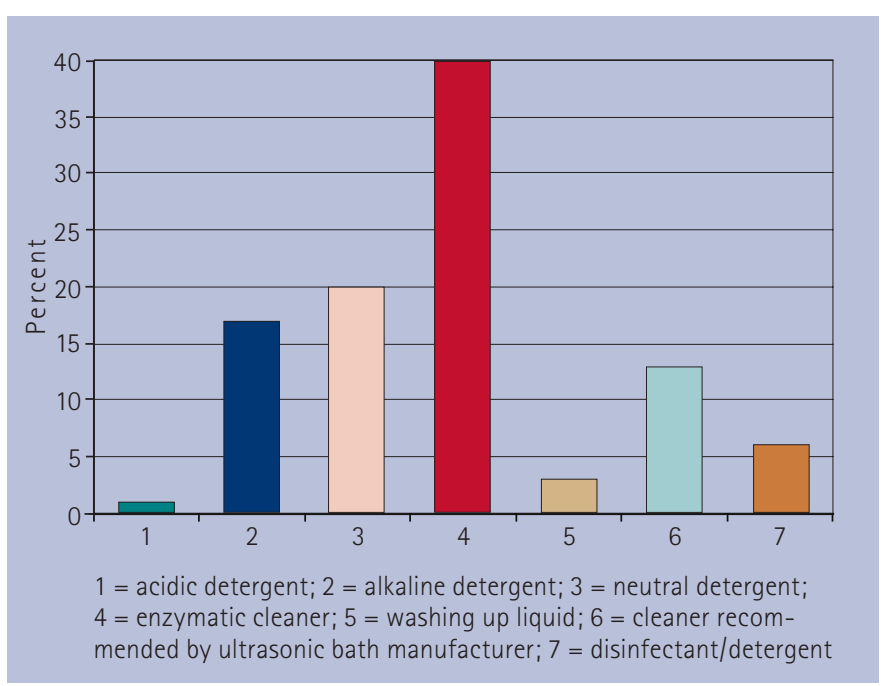

Fig. 2 Agents used in ultrasonic baths

\section{Manual washing}

Virtually all (96\%) of the surgeries used manual washing as either the sole method or as part of the cleaning process. Fortythree percent of the surgeries had a designated sink which was used only for instrument cleaning, but the remainder also used the sink for hand washing (84\%), beverage preparation (16\%) or environmental cleaning (34\%). The manual washing process was generally poorly controlled, with $41 \%$ of practices using no cleaning agent other than water. A range of cleaning agents was used (Fig. 1) but there was no standardisation of concentration or of the temperature of water used for cleaning. Only $2 \%$ of surgeries used a detergent formulated for manual washing of surgical instruments, with 37\% using surgical hand wash. Other miscellaneous agents used for cleaning included bars of soap, disinfectants and kitchen cleaning agents.
Of the surgeries in which instruments were manually washed, the range of brush types used to clean instruments included those with synthetic bristles (70\%), wire bristles (46\%), natural bristles (9\%) or pipe cleaners (8\%). Many surgeries used more than one type of brush. Other implements used to clean instruments were metal pot scourers (4\%) and nylon pot scourers $(3 \%)$. For cleaning of lumened devices, such as aspirator tips, $64 \%$ of surgeries used manual cleaning using brushes on a wire stem $(89 \%)$ or a pipe cleaner.

Only 14\% performed manual cleaning with the instruments entirely immersed to prevent aerosol generation, whilst $60 \%$ carried out manual washing entirely under running water. Rinsing of washed instruments was undertaken in $84 \%$ of surgeries. Only $1 \%$ of surgeries used a separate sink for rinsing and a further $2 \%$ rinsed in a bowl. In most cases, water from a holding tank or from the mains supply was used for rinsing. One percent of surgeries rinsed instruments with softened water and less than 1\% rinsed instruments with sterile water for irrigation. Eighty-five percent of the surgeries never dried instruments after manual cleaning.

\section{Ultrasonic cleaning of instruments}

Ultrasonic baths were present in $92 \%$ of surgeries. The age of the ultrasonic baths ranged from $<1$ to 14 years (median of three years old). Most (96\%) of the ultrasonic cleaners had removable lids and the majority of surgeries (92\%) operated the equipment with the lid in the closed position. Eighteen percent of surgeries had ultrasonic cleaners that incorporated a chamber drain.

The range of cleaning agents used in the ultrasonic baths is shown in Figure 2. The interval that elapsed between changes of the solution in the ultrasonic bath ranged from two to 504 hours (median nine hours) and 63\% emptied the ultrasonic bath at the end of the working day. Eighty percent of surgeries did not change the ultrasonic cleaning fluid at four hourly intervals or more frequently. In $11 \%$ of surgeries the interval was five days or more. However, 83\% of surgeries changed the ultrasonic bath solution when visibly soiled. After ultrasonic cleaning, $86 \%$ of surgeries rinsed their instruments with water, usually under running tap water.

Most (96\%) of the surgeries did not check the efficacy of the ultrasonic generator by means of the aluminium foil ablation test $^{22,23}$ (HTM/SHTM 2030). One surgery undertook periodic tests of the cleaning efficacy of the ultrasonic bath. ${ }^{22,23}$ For $9 \%$ of surgeries there was a defined loading pattern for the ultrasonic cleaner and in 8\% there was a defined maximum load.

\section{Instrument inspection}

Eighty-five percent of surgeries routinely inspected all instruments for cleanliness after the cleaning process. However, only $1 \%$ of surgeries had a magnifier available for inspection of small or intricate devices and 3\% had task lighting available for cleanliness inspections. The person performing the cleanliness inspection was invariably the same person who performed the cleaning. For 98\% of surgeries the inspection for cleanliness occurred immediately after cleaning.

In $46 \%$ of surgeries complex instruments were disassembled before inspection. In 52\% of surgeries cleaned instruments were checked or tested for functionality prior to use on patients. 


\section{Management, policies and procedures}

The BDA Advice Sheet A12, ${ }^{24}$ which covers aspects of instrument cleaning, was available in $79 \%$ of the surgeries visited. The remainder had no written infection control policy.

Less than $1 \%$ of surgeries kept records of which instruments had been washed and by whom. Ninety-nine percent of surgeries returned dirty items for re-cleaning, in 1\% of surgeries cleanliness failures were recorded and in 3\% of surgeries cleanliness failures were subject to review and analysis to establish the cause. In 6\% percent of surgeries the process of instrument cleaning had been audited, with $90 \%$ of these being internal audits and 10\% extrinsic audits.

\section{DISCUSSION}

The survey described in this paper has attempted to overcome the criticism levelled at many earlier questionnaire-based studies, that the data gathered on adherence to infection control procedures in dentistry were not sufficiently objective. ${ }^{20}$ The results of the present study are based on direct observation, by trained surveyors, of procedures within dental surgeries. They provide a very accurate representation of instrument cleaning processes in a randomly selected cohort of Scottish dental surgeries, which we believe to be representative of those found throughout the UK.

Manual cleaning of instruments remains a feature in most surgeries. However, the methods of implementation reveal a number of areas of concern, both in relation to the efficacy of cleaning and the risk of infection to staff undertaking the cleaning. More than half of the surgeries did not have a dedicated sink for instrument cleaning and in most cases the rinsing of instruments was undertaken in the same sink as instrument washing. In some cases the sinks used for instrument washing were also used for other purposes, such as beverage preparation and hand washing. Whilst the wearing of protective gloves was virtually universal, other personal protective equipment, such as eye protection, was used much less often. This is a particular concern, since more than $80 \%$ of the surgeries did not fully immerse the instruments underwater when cleaning, resulting in considerable opportunity for generation of aerosols.

In relation to staff health and safety this survey identified several shortcomings. To ensure that the cleaning of contaminated dental instruments complies with Health and Safety at Work Regulations and the Control of Substances Hazardous to Health Regulations, ${ }^{17,26}$ cleaning is required to be carried out in a manner that minimises the risk to staff from contamination on used devices and from the process chemicals. This should include identification of processes that produce or involve the use of substances hazardous to health (this includes potentially contaminated biological material). These risks should be contained by environmental controls to prevent dispersion, reduce exposure to sharps and ensure adherence to standard infection control precautions. Provision of personal protective equipment and emergency facilities such as eye wash baths and first aid kits are essential. In order to control and manage the risks of cross-infection, decontamination should be carried out only by trained staff. This is a requirement under the Health and Safety at Work legislation. ${ }^{17,26}$ There should be documented training procedures for all staff who carry out decontamination, accompanied by a record of training undertaken.
The training should include a competency assessment and be subject to periodic review and update. The results of this survey, in which approximately $10 \%$ of surgeries had documented evidence of training, suggests that improvements in the training and competency assessments of staff involved in the various stages of instruments decontamination is required.

Most dental practices are located in converted residential properties with limited space. Whilst many surgeries had attempted to create a dedicated area for decontamination, the lack of space severely impacted the efficiency and functionality of the decontamination area. Apart from other on-going activity in the decontamination area, it was of concern that $69 \%$ of surgeries had inadequate separation of clean and dirty areas and work flow patterns that could result in confusion between dirty instruments and those that had been cleaned and sterilised. It is also essential ${ }^{17,26}$ that the cleaning is performed in a manner that minimises the risk to third parties (patients), implying segregation of cleaning activities from the patient area. Ideally this should be a physical segregation of decontamination processes, in a dedicated decontamination area/ room separated from the patient treatment area by means of a wall. ${ }^{24,27-29}$ Alternative, but less satisfactory solutions include provision of ventilation to ensure flow of contamination away from patient treatment area or temporal separation of decontamination and clinical activity. ${ }^{2}$ Temporal separation may be achieved by performing different activities at different times together with rigorous environmental cleaning between different types of decontamination processing activity. However, this is very difficult to achieve in a busy dental practice.

Cleaning should be carried out by a validated process. of interest was the finding that no surgery was utilising an automated washer disinfector. This may be due to the relatively recent introduction of benchtop models and the lack of information in a form readily available to dental practitioners on the installation, use and operation of such equipment. Use of an appropriate washer-disinfector can increase productivity, improve cleaning efficacy and reduce staff exposure to contaminated sharps. ${ }^{30}$ However, care must be taken when purchasing this equipment to ensure compatibility with appropriate regulatory requirements. ${ }^{29,31}$ These machines must also be commissioned on installation and reports authorised by an Authorised Person. In addition the machine will be required to undergo periodic testing and an annual re-validation test. ${ }^{22,23,32}$

Manual cleaning is a very difficult process to control. There are many factors which can affect cleaning efficacy, including water temperature, cleaning agent chosen and the concentration of that agent. The results of this study highlight the problems of process management and quality control in the manual cleaning of instruments in dental practice. More than 40\% of the surgeries used no cleaning agent at all, other than water. The remaining surgeries used a wide range of agents, the most popular of which was surgical handwash, a preparation that is entirely inappropriate for instrument cleaning. Surgical handwash containing chlorhexidine adheres to protein rather than exerting a detergent action. Only a very small proportion (2\%) of surgeries used a detergent which was specifically formulated for cleaning surgical instruments. In none of the surgeries visited was the concentration of the cleaning agent or the water temperature standardised. If manual cleaning of dental instruments is to continue, then clearly defined procedures, which 
utilise appropriate materials and operating conditions, are essential. The use of wire bristle brushes and pot scourers to clean dental instruments is not recommended as they may lead to surface damage of the instruments which will initiate corrosion and impair subsequent reprocessing and functionality. ${ }^{33}$ Other cleaning implements should be single use or subjected to a thorough cleaning after use. The cleaning of lumened devices, for example aspirator tips, is difficult due to access for cleaning and inspection; these types of devices can readily and cost-effectively be replaced by single use alternatives.

Ultrasonic baths were widely available in the surgeries visited and were often used in conjunction with manual cleaning. Once again there was a wide range of operating procedures for these. Only 20\% of surgeries changed the fluid in the ultrasonic bath at the end of each clinical session, although significantly more (63\%) emptied the ultrasonic bath at the end of each working day. It is recommended that ultrasonic baths should be emptied at least every four hours, or more frequently if heavily soiled. ${ }^{34}$ The chemicals used in the ultrasonic baths were usually alkaline, neutral, enzymatic or manufacturer's own brand detergent, each of which is acceptable, provided they concur with instrument manufacturer's instructions. The use of washing up liquid and disinfectants is not recommended since these formulations have not been validated for surgical instruments and in the case of disinfectant solutions their use may result in protein fixation to instruments. In order to ensure efficacy of the cleaning process regular testing of the functionality of ultrasonic baths is important. However, it was rare to find periodic testing of the ultrasonic generator or cleaning efficacy tests being performed..$^{22,23}$ It is difficult to quantify the efficacy of the cleaning process without evidence that the ultrasonic machine is actually working.

All cleaned devices should be inspected for debris after cleaning and prior to sterilisation. Due to the large number of small, intricately designed instruments in dentistry, the use of an illuminated magnifier is recommended. Previous studies have demonstrated that dental instruments are often contaminated following reprocessing. ${ }^{5,6,8,9}$ Whilst the majority of surgeries claimed to inspect their instruments after cleaning, only $1 \%$ had a magnifier available for inspection of instruments.

Overall control of the decontamination process should be managed by a defined person within the practice using quality assurance principles. This person should have a demonstrable competence to manage this process in dental practice. Written procedures should define, document and control all the stages of cleaning, should be readily available to personnel undertaking the cleaning and be up to date with guidance. Although many practices had access to the BDA Advice Sheet A12, ${ }^{24}$ this document provides little in the way of detailed procedures and quality assurance to help staff undertake effective cleaning of dental instruments.

In conclusion, many of the procedures used for the cleaning of re-usable dental instruments in general dental practice do not conform to extant guidance and increase the risk of transmission of infection. This is of particular concern, since cleaning is a key stage in the sterilisation process and in reducing the risk from onward transmission of vCJD. Where possible, practices should review the many options available to them for the reprocessing of dental instruments. In some circumstances this may involve the use of centralised reprocessing facilities ${ }^{35}$ or single use instruments. Other options may involve a compromise with local reprocessing of expensive devices such as dental handpieces and centralised reprocessing of other instruments. If local reprocessing of dental instruments is to continue in general dental practice, clearly much work is needed to help the dental team improve the cleaning process for dental instruments. This should take the form of education and training programmes and the development of a clearer management process using quality assurance principles. The findings of this survey also have profound financial implications for dental practices, not least in the provision of dedicated decontamination areas and automated washer disinfectors. This also represents an opportunity for improvement, especially with the planning of new dental units. However, if the opportunity is to be fully realised, there is a requirement for sufficient infrastructure to support practitioners in implementation of improvements in local decontamination, ${ }^{29}$ for example expert review of new buildings, commissioning and testing of decontamination equipment. Practice-friendly guidance to help practitioners meet the various regulatory requirements for cleaning dental instruments is essential if progress is to be made in this very important area of clinical practice.

This research was supported by a grant from the Scottish Executive Health Department. Funding for the training of the survey team members was provided by NHS Education for Scotland. The authors thank Mr Ray Watkins, Chief Dental Officer for Scotland and Dr Jim Rennie, Postgraduate Dental Dean for Scotland for support of the study, the members of the survey teams and the dental practitioners and nurses who agreed to be surveyed.

1. Dinakaran $S$, Kayarka W. Debris on processed ophthalmic instruments: a cause for concern. Eye 2002; 16: 281-284.

2. Ramakrishna B S. Safety of technology: infection control standards in endoscopy. J Gastroenterol Hepatol 2002; 17: 361-368.

3. Kibria S M G, Kerr K G, Dave J, Gough M J, Homer-Vanniasinkam S, Mavor A I D. Bacterial colonisation of Doppler probes on vascular surgical wards. Eur J Vasc Endovasc Surg 2002; 23: 241-243.

4. Golder M, Chan C L H, O'Shea S, Corbett K, Chrystie I F, French G. Potential risk of cross infection during peripheral-venous access by contamination of tourniquets. Lancet 2000; 355: 44.

5. Lowe A H, Bagg J, Burke F J T, MacKenzie D, McHugh S. A study of blood contamination of Siqueland matrix bands. Br Dent J 2001; 192: 43-45.

6. Smith A, Dickson M, Aitken J, Bagg J. Contaminated dental instruments. J Hosp Infect 2002; 51: 233-235.

7. Weightman N C, Lines L D. Problems with the decontamination of dental handpieces and other intra-oral dental equipment in hospitals. $J$ Hosp Infect 2004; 56: 1-5.

8. Smith A J, Letters S, Lange A, Perrett D, McHugh S, Bagg J. Residual protein levels on reprocessed dental instruments. J Hosp Infect 2005; 61: 237-241.

9. Letters S, Smith A J, McHugh S, Bagg J. A study of visual and blood contamination on reprocessed endodontic files from general dental practice. Br Dent J 2005; 199: 522-525.

10. Economics, Statistics and Operational Research Division, Department of Health. Risk assessment for VCJD and dentistry. London: The Stationery Office, 2003. (www.doh.gov.uk/cjd/dentistryrisk/index.htm)

11. Economics, Statistics and Operational Research Division, Department of Health. Assessing the risk of VCJD transmission via surgery: an interim review. London: The Stationery Office, 2005.

12. Frosh $F_{\text {, Joyce }} R_{1}$ Johnson $A$. latrogenic VCJD from surgical instruments. Br Med J 2001; 322: 1558-1559.

13. Favero M S, Bond W W. Chemical disinfection of medical and surgical material. In Block S S (ed) Disinfection, sterilization and preservation. 5th ed. pp 881-917. Philadelphia, PA: Lippincott Williams \& Wilkins, 2001.

14. Parker $\mathrm{H} \mathrm{H}$ 4th, Johnson $\mathrm{R}$ B. Effectiveness of ethylene oxide for sterilization of dental handpieces. J Dent 1995; 23: 113-115.

15. Alfa M J, Olson N, Degagne P, Hizon R. New low temperature sterilization technologies: microbiocidal activity and clinical efficacy. In Rutula W A (ed) Disinfection, sterilization and antisepsis in healthcare. pp 67-78. Champlain, NY: Polyscience Publications, 1998

16. Rutula W A, Weber D J. Clinical effectiveness of low temperature sterilization technologies. Infect Control Hosp Epidemiol 1998; 19: 798-804.

17. Health and Safety at Work etc Act 1974. London: HMSO, 1974.

18. Consumer Protection Act 1998 (Product Liability). London: HMSO, 1998. 
19. Medical Devices Regulations 2002. London: HMSO, 2002

20. Gordon B L, Burke F J T, Bagg J, Marlborough H S, McHugh E S. Systematic review of adherence to infection control guidelines in dentistry. J Dent 2001; 29: 509-516.

21. Smith A, Hurrell D, Bagg J, McHugh S, Mathewson H, Henry M. A method for surveying instrument decontamination procedures in general dental practice. $\mathrm{Br}$ Dent J advance online publication, 9 February 2007 (DOI: 10.1038/bdj.2007.125).

22. NHS Scotland Property and Environmental Forum. SHTM 2030: Washer disinfectors. Edinburgh: HMSO, 2001.

23. NHS Estates. HTM 2030: Washer disinfectors. London: HMSO, 1997.

24. British Dental Association. Advice Sheet A12. London: BDA, 2003.

25. The Glennie framework: the decontamination of surgical instruments and other medical devices. Report of a Scottish Executive Health Department Working Group. Edinburgh: HMSO, 2001. (www.show.scot.nhs.uk/sehd/publications/ Glennieframework.pdf).

26. Management of Health and Safety at Work Regulations 1999. London: HMSO, 1999.

27. Centers for Disease Control and Prevention. Guidelines for infection control in dental health care settings - 2003. MMWR Recomm Rep 2003; 52 (RR-17): 1-61.
28. NHS Estates, Department of Health. A protocol for the local decontamination of surgical instruments. London: HMSO, 2004. (www.decontamination.nhsestates. gov.uk/downloads/local_decontamCompleteversionMay2004v2.doc).

29. Health Protection Scotland. Local decontamination units: guidance on the requirements for equipment, facilities and management. Glasgow: Health Protection Scotland, 2005. (http://www.documents.hps.scot.nhs.uk/hai/decontamination/publications/ldu-001-02.pdf)

30. Miller C H, Tan C M, Beiswanger M A, Gaines D J, Setcos J C, Palenik C J. Cleaning dental instruments: measuring the effectiveness of an instrument washer/disinfector. Am J Dent 2000; 13: 39-43.

31. Smith A J. Buyers beware. Br Dent J 2003; 195: 621.

32. prEN ISO 15883 parts 1-4. Washer disinfectors.

33. Proper maintenance of instruments. 8th ed. Mörfelden-Walldorf: AKI, 2004. (www.a-k-i.org).

34. NHS Scotland. Decontamination of reusable medical devices: control of aqueous solutions in ultrasonic cleaners. Safety Action Notice 03/11. Edinburgh: NHSScotland, 2003

35. Wilson A P R, Brent D, Beckett G. Benchtop sterilizers and CSSD. J Hosp Infect 1999; 43: 246-247. 